IN MEMORIAM

\title{
Kreek, Mary Jeanne In Memoriam
}

Charles $\mathrm{O}^{\prime}$ Brien $^{1 凶}$

(c) The Author(s), under exclusive licence to American College of Neuropsychopharmacology 2022

Neuropsychopharmacology (2022) 47:1137; https://doi.org/10.1038/s41386-021-01061-y

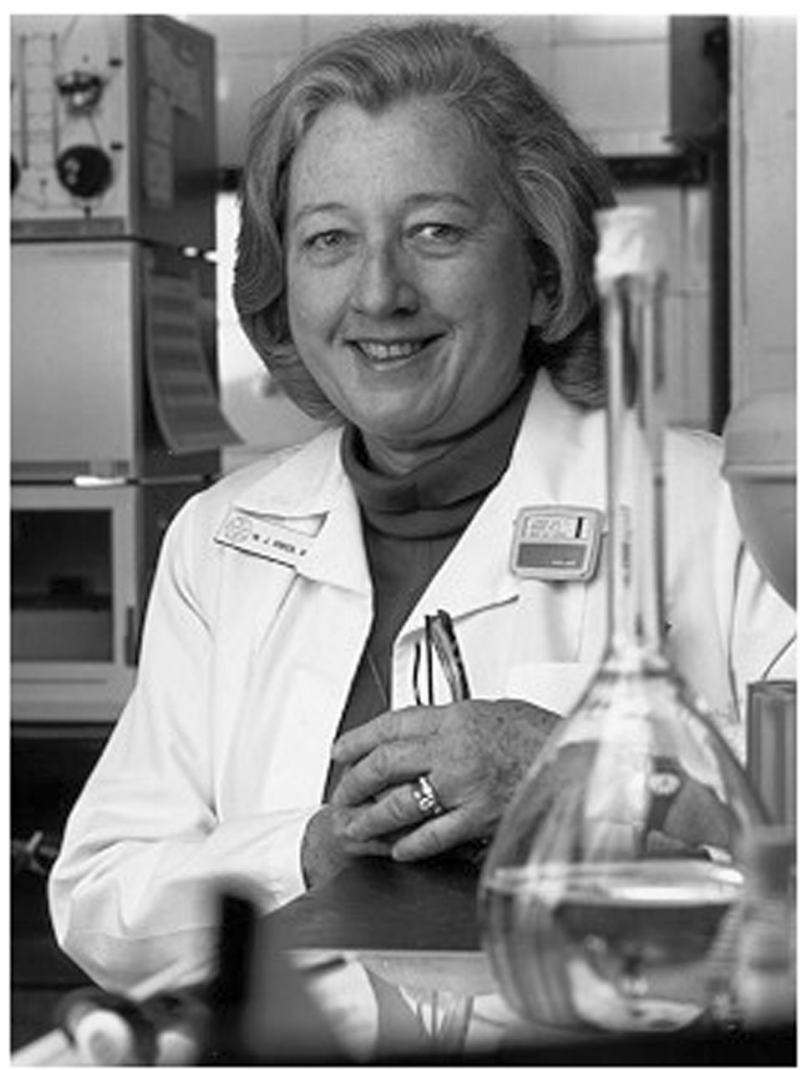

Mary Jeanne, a Fellow Emeritus in the ACNP, knew from an early age that she wanted to become a physician and scientist, but her first part time job was as a professional dancer. She had a bout with paralytic polio at an early age and subsequently used ballet exercises as a form of physical therapy. She was active in science fairs while in high school and was a finalist in the "Westinghouse Science Talent Search".

Mary Jeanne was born in Washington DC and grew up there. After college at Sarah Lawrence, she attended Medical School at Columbia and Internal Medicine Residency in a male-dominated program at Cornell. Her excellence in the residency was noticed and she was selected in 1963 for a special research fellowship with Vincent Dole who had just started a project on heroin addiction. Dole was trying a completely novel approach to this untreatable problem by testing the heroin-like drug, methadone, as a new treatment. His group discovered that methadone reduced drug craving and compulsive heroin-seeking thereby allowing the heroin addicts to function normally in school and in occupations. Mary Jeanne added clinical precision to the team that also included the psychiatrist, Marie Nyswander.

From the mid 1960's to her death this year, Mary Jeanne never ceased to improve and develop methadone treatment. She was the key defender of this treatment that was proven to save lives and allow rehabilitation of heroin addicts. While many continued to criticize the concept of simply transferring the patient from one opioid, heroin, to a longer acting opioid, methadone, without achieving a stable drug-free state, Mary Jeanne et al. produced evidence that maintenance on methadone allowed true rehabilitation.

Throughout her career Mary Jeanne led the movement toward studying the genetic basis of opioid addiction. Her work was recognized by numerous awards including the top award from the College on Problems of Dependence, the Eddy Award in 1999. She also received the Lifetime Achievement Award from the National Institute on Drug Abuse in 2014. She served several terms as chair of the Committee on Problems of Drug Dependence and as a member of ACNP council in 2002.

Mary Jeanne married Robert Schaeffer in 1970. Bob was a specialist in liver disease who attended scientific sessions at ACNP and CPDD and was well known in both organizations. They had two children and four grandchildren. Their daughter Esperance is currently a productive physician-scientist at Massachusetts General Hospital.

Throughout her career Mary Jeanne Kreek had a major positive impact not only on the scientific field of addictive disorders, but also on the societal approach to this continuing severe public health problem. When politicians needed advice on substance abuse, Mary Jeanne was always among the most influential voices. The problems of addiction are international and Mary Jeanne had a large international footprint, especially with students and trainees from Europe.

${ }^{1}$ University of Pennsylvania, Philadelphia, PA, USA. ${ }^{凶}$ email: Obrien@pennmedicine.upenn.edu

Received: 4 June 2021 Accepted: 4 June 2021

Published online: 31 January 2022 